\title{
First record of the little-known land gastropod genus Nobuea Kuroda et Miyanaga, 1943 (Gastropoda Diplommatinidae) from Jeju Island, South Korea
}

\author{
Kazuki Kimura' \& Ron Noseworthy ${ }^{2}$
}

\begin{abstract}
${ }^{1}$ Research Institute for Ulleung-do and Dok-do islands, Department of Biology, Kyungpook National University, 80 Daehak-ro, Buk-gu, Daegu, 41566, Republic of Korea; email: k.kimura.000@gmail.com

${ }^{2}$ School of Marine Biomedical Science, Jeju National University, 66 Jejudaehakno, Jeju, 690-756, Republic of Korea; email: rgnshells@yahoo.ca
\end{abstract}

ABSTRACT

Nobuea Kuroda et Miyanaga, 1943 (Gastropoda Cyclophoridae) is one of the least-known genera of terrestrial gastropods. An individual of this genus was collected from Jeju Island, South Korea, the first record of Nobuea from this island. Further studies are needed to investigate the taxonomic and conservation status of the Jeju Nobuea reported here.

KEY WORDS

Conservation; nonmarine gastropods; insular biodiversity; new records; geographic distribution.

Received 14.12.2019; accepted 01.03.2020; published online 26.03.2020

\section{INTRODUCTION}

The genus Nobuea Kuroda et Miyanaga, 1943 (Gastropoda Diplommatidae) represents one of the least-known genera of land gastropods. There are two recognized species of this genus: $N$. elegantistriata Kuroda et Miyanaga, 1943 and N. kurodai Minato et Tada, 1978.

The first species was described based on a single specimen collected on Geomun Island, South Jeolla Province, South Korea (Kuroda \& Miyanaga, 1943) and no living individual has been encountered at least for the last three decades (National Institute of Biological Resources, South Korea, 2012). In the Korean literature, few illustrations of N. elegantistriata occur, e.g., Kwon et al., (1993; 2001), Min et al., (2004) and Lee \& Min (2005). The illustration in Kwon et al., (2001) is repeated in the two subsequent publications. $\mathrm{No}$ buea kurodai was recorded from Tushima-cho, Ehime Prefecture, Japan (Minato \& Tada, 1978) and, subsequently, an additional population was found on Mt. Kamon, Miyazaki Prefecture, Japan (Minato \& Nishi, 1996).

At present, as far as we know, only five individuals of this species have been reported (four from the type locality and one from the second population). Because of the low population densities and/or restricted distributions, both Nobuea species are listed in national level red data books (National Institute of Biological Resources, South Korea, 2014; Ministry of Environment, Japan, 2019).

Jeju Island is the largest island in South Korea, with an area of about $1800 \mathrm{~km}^{2}$, and is situated about $80 \mathrm{~km}$ south of the Korean peninsula. The non-marine gastropod fauna of this island has been relatively well examined (e.g., Habe \& Kosuge, 1970; Noseworthy et al., 2007). At present, 52 species of land snails and eight freshwater snails have been recorded from Jeju Island (Habe \& Kosuge, 1970; Joo et al., 1979; Noseworthy et al., 2007; Kimura et al., in press). 


\section{MATERIAL AND METHODS}

On 10 October 2018, a field survey was conducted, and a single specimen of the genus Nobuea was collected at the parking lot of Geolmae Eco Park, Seogwipo, Jeju Special Self-governing Province $\left(33^{\circ} 14^{\prime} 53.9^{\prime \prime \prime} \mathrm{N} 126^{\circ} 33^{\prime} 15.1\right.$ '”) (Fig. 1). Its shell was examined under a light microscope. Because the specimen was preserved in $100 \%$ ethanol soon after being collected, the details of its anatomy were not obtained. The examined specimen was deposited in the personal collections of K. Kimura (Voucher No: MNKS2551)

\section{RESULTS AND DISCUSSION}

\section{Systematics}

Phylum MOLLUSCA Cuvier, 1797
Classis GASTROPODA Cuvier, 1795

Subclassis CAENOGASTROPODA Cox, 1960

Ordo ARCHITAENIOGLOSSA Haller, 1890

Superfamilia CYCLOPHOROIDEA Gray, 1847

Familia DIPLOMMATINIDAE Pfeiffer, 1857

Genus Nobuea Kuroda et Miyanaga, 1943

\section{Nobuea sp.}

DESCRIPTION. Shell small, strongly depressed, thin, rather dull white. Measurements: height 1.8 $\mathrm{mm}$, width $4.0 \mathrm{~mm}$ (Fig. 2, Voucher No: MNKS2551). Whorls three, with regularly increasing diameter. Protoconch with $1 \frac{1}{2}$ whorls, with smooth, glossy surface. Teleoconch finely rib-striated at irregular intervals, lower whorls more densely than upper ones. Ribs not parallel; spiral striae absent. Aperture circular, slightly oblique. Periphery round. Suture deep. Umbilicus wide and

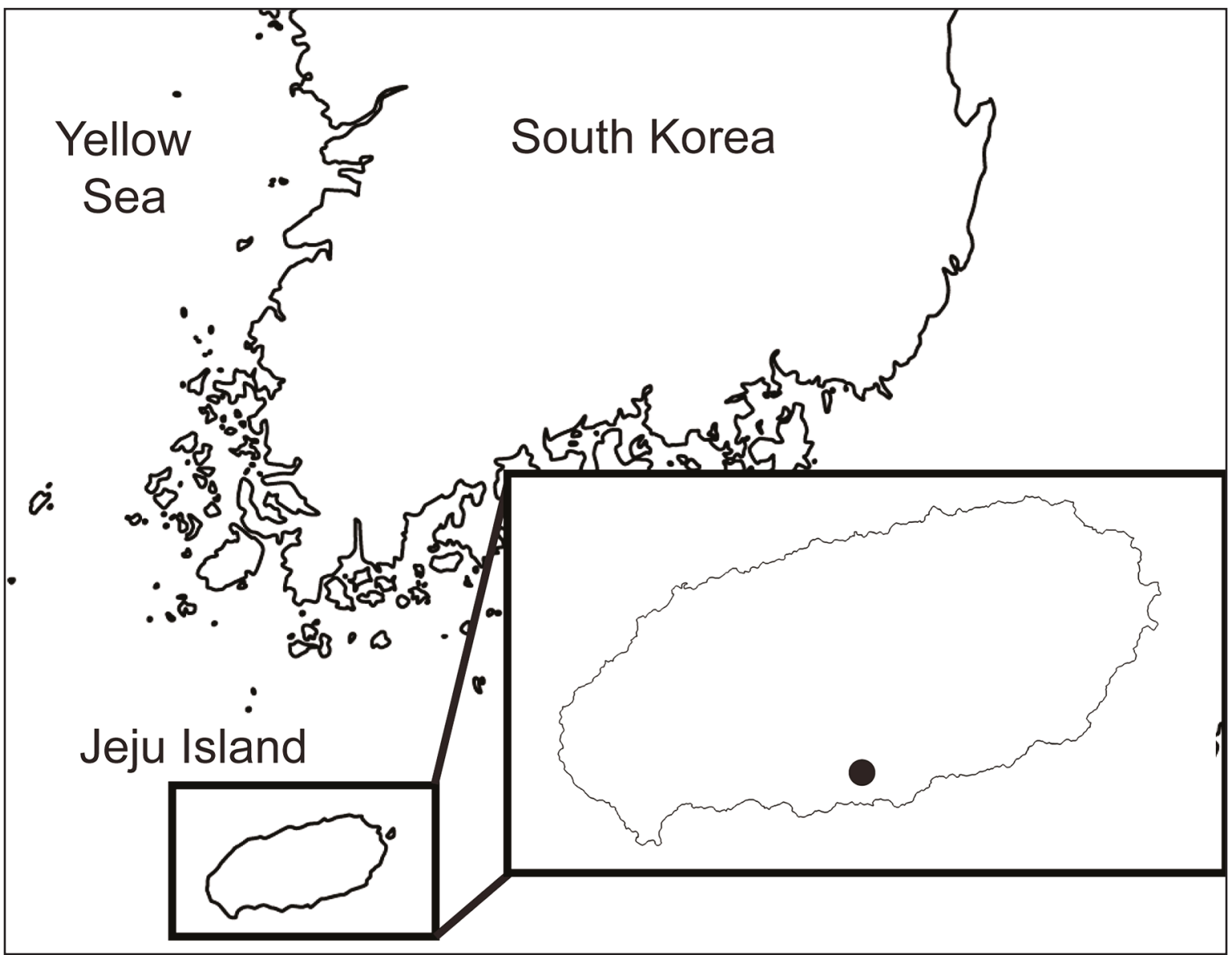

Figure 1. Sample collection locality in Jeju Island, South Korea. 
deep, showing the upper whorls within. Operculum circular, thin, not calcareous, with multiple spiral lines.

Distribution And Biology. The genus Nobuea is known from two Korean islands (Geomun and Jeju Islands) and western Japan (Ehime and

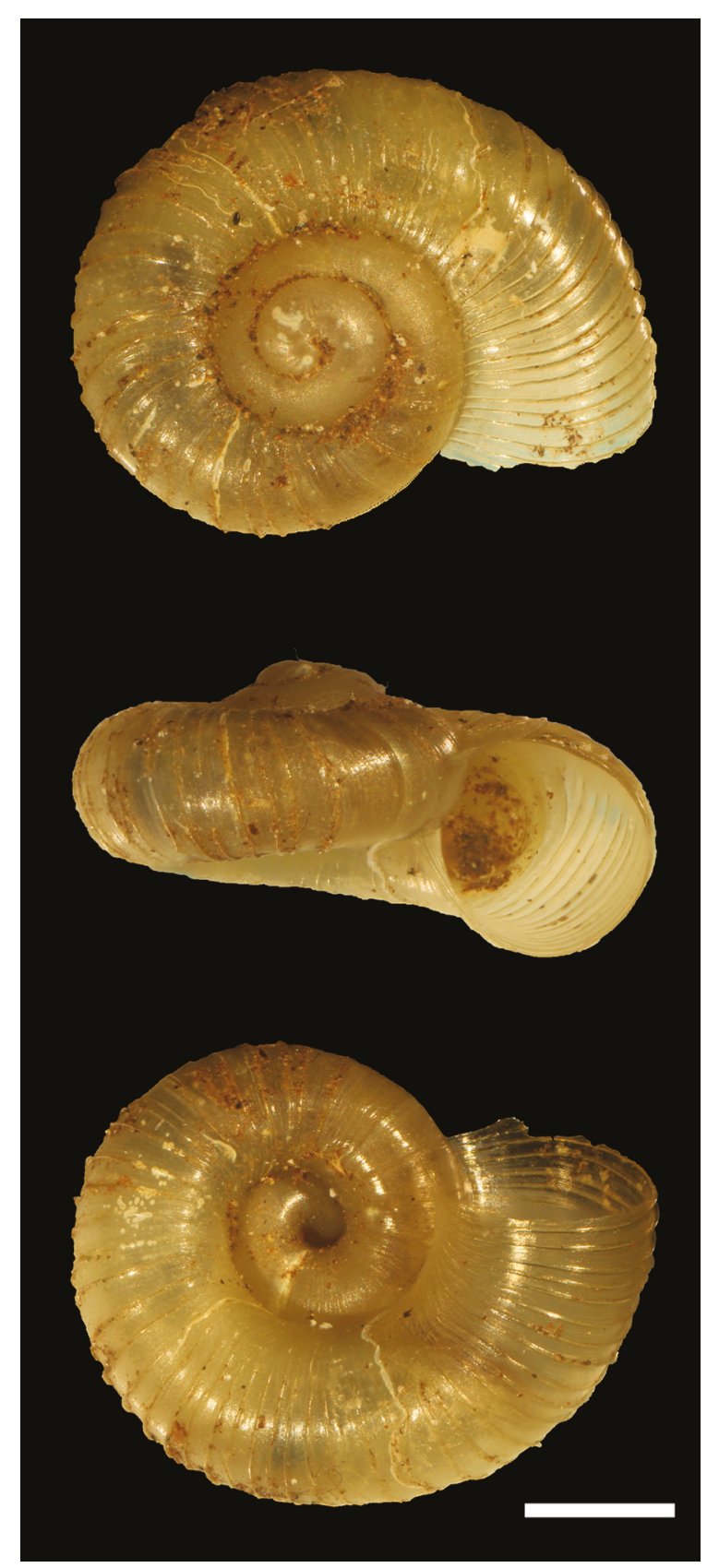

Figure 2. Shell of the Nobuea specimen collected on Jeju Island. Scalebar: $1.0 \mathrm{~mm}$.
Miyazaki Prefectures). There is few information on the ecology and life history of this genus.

REMARKS. The specimen examined here was probably an immature individual, and therefore adult shell size, shape, and anatomy of mature individuals remain to be elucidated. However, the specimen exhibited distinct differences from the two other Nobuea species. The Jeju Nobuea has a flatter shell, with fewer and more prominent ribs on its shell surface than found in N. elegantistriata and Nobuea kurodai. In addition, the Jeju Nobuea can be distinguished from $N$. elegantistriata by its larger shell size. Further studies using additional adult specimens are needed to confirm the taxonomic status of this Nobuea. It should be noted that the taxonomic position of the genus Nobuea is still controversial (Kwon et al., 1993; Azuma, 1995; Minato \& Nishi, 1996). Although the original description by Kuroda \& Miyanaga (1943) places $N$. elegantistriata in Diplommatinidae, Kwon et al., (1993) include it in the Alycaeidae. Subsequently, Minato \& Nishi (1996) and more recent publications regard the genus Noubea as a member of the Cyclophoridae. In this study, we placed the genus in Diplommatinidae in accordance with Kuroda \& Miyanaga (1943).

\section{ACKNOWLEDGEMENTS}

We express our sincere gratitude to Joy Noseworthy for considerable assistance in the field survey, and Daishi Yamazaki for providing the information on Japanese Nobuea. This research was supported by Basic Science Research Program through the National Research Foundation of Korea (NRF) funded by the Ministry of Education (2016R 1 A6A1A050119 10).

\section{REFERENCES}

Azuma M., 1995. Colored illustrations of the land snails of Japan, Revised edition. Hoikusha, Osaka, Japan, 343 pp.

Habe T. \& Kosuge S., 1970. Land and freshwater molluscs of the Tsushima Islands between Kyushu and Korea. Memoirs of the National Science Museum, 3: 305-320. 
Joo I.Y., Kwon O.K. \& Habe T., 1979. The land snails in Island Chejudo. Korean Journal of Limnology, 12: $35-40$.

Kimura K., Chiba S. \& Pak J.H., in press. Discovery of Gastrocopta armigerella (Reinhardt, 1877) (Gastropoda: Gastrocoptidae) from Jeju Island, South Korea. Molluscan Diversity.

Kuroda T. \& Miyanaga M., 1943. Land shell fauna of Kyobunto (Port Hamilton), Korean Archipelago. Venus, 12: 119-129.

Kwon O.G., Min D.K., Lee J.R., Lee J.S., Je J.G. \& Choe B.L., 2001. Korean Mollusks with Color Illustrations. Hangul Graphics, Busan, South Korea, 332 pp.

Kwon O.G., Park G.M. \& Lee J.S., 1993. Colored Shells of Korea. Academy Publishing Co., Seoul, 445 pp.

Lee J.S. \& Min D.K., 2005. Freshwater shells and land gastropods. Min Shellfish Research Institute, Seoul, $134 \mathrm{pp}$.

Min D.K., Lee J.S., Koh D.B. \& Je J.G., 2004. Mollusks in Korea. Min Molluscan Research Institute, Seoul, $566 \mathrm{pp}$.

Minato H. \& Nishi K., 1996. A note on second occur- rence of Nobuea kurodai (Mesogastropoda: Cyclophoridae) from Miyazaki-ken. Chiribotan, 27: 1415.

Minato H. \& Tada A., 1978. Nobuea, a genus of operculate Gastropoda new to Japan (Mesogastropoda; Diplommatinidae). Venus, 36: 168-170.

Ministry of Environment, Japan, 2019. Japanese Ministry of the Environment Red List 2019. https://www. env.go.jp/press/files/jp/110615.pdf Electronic version accessed 31 Aug 2019.

National Institute of Biological Resources, South Korea, 2012. Red data book of endangered mollusks in Korea. National Institute of Biological Resources, Seoul, 107 pp.

National Institute of Biological Resources, South Korea, 2014. Korean red list of threatened species, 2nd edition. National Institute of Biological Resources, Seoul, 246 pp.

Noseworthy R.G., Lim N.R. \& Choi K.S., 2007. A catalogue of the mollusks of Jeju Island, South Korea. Korean Journal of Malacology, 23: 65-104. 